\title{
Detecting and Measuring Back Disorders in Nonverbal Individuals: The Example of Domestic Horses
}

\author{
Clémence Lesimple $^{1,2, *}$, Carole Fureix ${ }^{1}$, Lydiane Aubé ${ }^{1}$, \& Martine Hausberger $^{2}$ \\ ${ }^{1}$ Ethologie Animale et Humaine, Université de Rennes \\ ${ }^{2}$ CNRS, Ethologie Animale et Humaine UMR Université de Rennes \\ *Corresponding author (Email: lesimple.c@gmail.com)
}

Citation - Lesimple, C., Fureix, C., Aubé, L., \& Hausberger, M. (2016). Detecting and measuring back disorders in nonverbal individuals: The example of domestic horses. Animal Behavior and Cognition, 3(3), 159-179. doi: 10.12966/abc.05.08.2016

\begin{abstract}
Back disorders are amongst the major health-related disorders associated to working conditions in our society. Horses share with humans the exposure to potential physically harmful working conditions leading to back disorders. However, despite their high prevalence, these problems are often unacknowledged in the horse industry, mostly because their diagnosis remains difficult, particularly in field conditions. In the present review, we review the current scientific knowledge on back vertebral, muscular and musculoskeletal disorders. We will first present the existing knowledge about their prevalence and the tools available for diagnosis. Then, the different potential sources of back pain, including anatomical implications, the effect of emotionality and working conditions will be discussed. We finally present the existing behavioral, postural and physiological indicators of back pain that could help an early detection of back disorders.
\end{abstract}

Keywords - Horse, Equine, Work, Illness, Back disorder assessment, Indicators

Sickness is defined as a state of unwellness, distress or disgust (Oxford Guide of the English Language, 1984), combining physical and emotional disorders. Sickness induces aversive experiences that range from mild discomfort to acute pain, which are mechanisms preventing the organism from incurring injuries (Bateson, 1991). According to this definition, the term "sickness" fits very well with back disorders. In humans, the presence of back disorders is related to increased aggressiveness (Berkowitz, 1993) and/or depression (Curie \& Wang, 2004; Garon \& Leavitt, 1983) and lower back pain is amongst the main causes of sick leave (Dionne et al., 2005). Back disorders may be caused by strictly physical parameters, such as bony dysfunction or malformations. However, working conditions are more and more often identified as a major source of back pain in humans (Banibrata, 2014; Widanarko, Legg, Devereux, \& Stevenson, 2014), related to postural or psychological constraints.

In horses too, physical malfunctions and malformations are possibly involved in some back related disorders (Haussler, 1996; Stubbs et al., 2006). However, working conditions, have also been proposed as further sources of such disorders (Fonseca et al., 2006; Gillis, 1999; Haussler, 1997; Jeffcott, 1980): horses share with humans working activities that may cause psychological (e.g., suppression of emotions) and physical stress (e.g., physical constraints; McGreevy \& McLean, 2005). In this review, we present the current knowledge about the prevalence of back disorders and the tools used to diagnose them. We will review the potential causes of back disorders with a special highlight on working conditions. Psychological, physical and anatomical impacts of riding will be discussed in relation to the presence of visible indicators of back disorders. Finally, as the presence of back disorders is one of the main 
pathologies in horses, we will review the validated indicators of back disorders as well as the signals that are not always specific of back disorders but should be considered as warning signals.

\section{Back Disorders: Prevalence and Diagnosis Tools}

Back disorders are one of the most common illnesses in horses under domestic conditions and musculoskeletal disorders at the back level have been identified in the past as one of the main reasons for horses' euthanasia (Johnson et al., 1994; Mohammed, Hill, \& Lowe, 1991). Since then, these findings were confirmed (Egenvall, Penell, Bonnett, Olson, \& Pringle, 2006; Wallin, Strandberg, Philipsson, \& Dalin, 2000), and the prevalence $(0.9-100 \%)$ of horses with back disorders in the recent studies (Fonseca et al., 2006; Fureix, Menguy, \& Hausberger, 2010; Lesimple et al. 2012, 2013; Stubbs et al., 2006) are in accordance with those of the 80's (Haussler, 1996; Jeffcott, 1980). On the basis of a necropsy anatomical study on 443 horses, Jeffcott (1980) had found that $77.6 \%$ of the horses had vertebral problems that may have induced pain. Most problems were found in $6-8$ year old horses, in geldings rather than stallions or females, and in thoroughbreds rather than in other breeds. Show jumping and eventing horses were more affected than horses of other disciplines. Yet, the term "back disorders" is vague and underlying problems include both purely physical causes such as anatomical abnormalities (i.e., vertebral formulae: number of cervical, thoracic, lumbar and sacral vertebrae, spinal junctions malformation, Haussler, 1997; Jeffcott, 1979; Zimmermann, Dyson, \& Murray, 2011) or deriving musculoskeletal impairments and secondary causes, i.e. due to environmental conditions (e.g., vertebral impingement, fractures, articular attrition, muscular and tendinous impairment, Fonseca et al., 2006; Haussler, 2000).

Both emotional tensions (Ridgway \& Harman, 1999) and physical constraints of work (Gillis, 1999; Jeffcott, 1979, 1980) have been pointed out by veterinarians as potential major sources of back disorders. In sport horses, poor performance and lameness are the primary reasons leading owners and riders to ask for their horses' examination and back disorders are only secondarily diagnosed (Fonseca et al., 2006; Haussler, 1996; Jeffcott, 1975, 1980; Stubbs et al., 2006; Varcoe-Cocks, Sagar, Jeffcott, \& McGowan, 2006). One of the main limitations for back disorders reports is that their clinical detection is difficult. Medical imaging techniques allow the detection of healthy or damaged musculoskeletal areas (Nagy, Dyson, \& Barr, 2010; Stubbs et al., 2006; Tucker, Schneider, Sondhof, Ragle, \& Tyler, 1998). However, the size of the patient and thickness of surrounding tissues limits the efficiency of radiographic imaging (Cauvin, 1997; Head, 2012) and ultrasonic or scintigraphic techniques are limited by subcutaneous fat, require specific equipment, and are difficult to organize in field conditions (Cauvin, 1997; Gillis, 1999; Head, 2012). Studying kinematics of the spine requires standardized controlled conditions, expensive equipment (Faber et al., 2000; Haussler \& Erb, 2006; Licka \& Peham, 1998) and raises the ethical question of implanting subcutaneous markers into the horses' body. Manual palpation allows a global evaluation of the spinal health based on spinal mobilization and palpable areas of muscle hypertonicity (Kirkaldy-Willis \& Cassidy, 1985; Sullivan, Hill, \& Haussler, 2008) and has proven useful to detect horses' vertebral disorders in several studies (Fureix et al., 2010; Haussler, 1997; Jönsson et al., 2013; Lesimple et al., 2010, 2012, 2013). However, it remains subjective, although inter-practitioners' agreement was very high (94 to 100\%) in Lesimple et al. $(2012,2013)$ and also very constraining because it requires the presence of a trained professional. The pressure algometer (PA) enables the examiner to quantify the subjective assessment of pain pressure threshold and makes it possible to locate the painful sites with precision (Haussler \& Erb, 2006). It can relate pain severity and vertebral lesions and is in agreement with manual palpation evaluations (Varcoe-Cocks et al., 2006). However, the results are based on the evaluation of "pain reactions", which are not clearly defined. Overall thus, there is a lack of objective tools allowing the detection of back disorders in the field and on large samples of animals.

\section{Is Electromyography a Novel Promising Tool for Back Disorders’ Assessment?}


Measurement of muscular activity is one of the recent tools successfully used to detect low back pain in human patients (Arena, Sherman, Bruno, \& Young, 1989, 1991). Therefore, we wondered whether it could be also a useful tool for detecting horses' back disorders (Lesimple et al., 2012). Eighteen riding school horses were examined by practitioners (Kappa agreement between practitioners: $97.7-100 \%$ ) and submitted to sEMG evaluation using a wire free device (static surface electromyography: Myovision ${ }^{\odot}$ ). Both the practitioner and the experimenter were blind to the other measures' results. The evaluations were made outside the riding schools' activity. Horses were led with a rope, standing, slightly restrained. The practitioner evaluated the mobility of the vertebrae all along the spine. For the sEMG evaluation, the experimenter had two joysticks with five electrodes on each, designed to record the muscular electric activity close to the spine, at the level of the vertebrae before and after the joystick location (if the joystick was placed on the third cervical, the electrodes measured the muscular activity close to $\mathrm{C} 2$ and C4). The information was then sent to a receptor linked to a computer. Measurements were made with the horse standing straight on a flat ground, with the forelegs and rear legs on the same line. The overall evaluation of the spine was highly correlated between practitioners' and sEMG assessment: horses with more vertebral sites affected according to manual palpation (\% of affected vertebral sites) were also those with more dorsal sites affected according to sEMG measurement. Both evaluations gave similar proportions of severely affected (55\% and 50\%) and healthy (39\% and 39\%) horses. sEMG values were higher around vertebral sites that had been detected as affected by the practitioners' evaluations than at "healthy" sites. Electromyography may well be a very interesting new tool for assessing back disorders in horses as it is in humans where higher values are signals of back pain.

\section{Sources of Back Disorders: Anatomy, Emotions and Work}

The "normal" horse's spine is composed of 7 cervical, 18 thoracic, 6 lumbar, 5 sacral and 15 to 18 caudal vertebrae, but post mortem studies have revealed inter-individual variations in these numbers, particularly around the lumbar and sacral areas (Haussler, 1997; Jeffcott, 1979; Stubbs et al., 2006; Townsend, 1987). Haussler (1996) found that amongst 36 racehorses examined, 39\% had either one lumbar vertebrae missing or one additional sacral, $22 \%$ had abnormal shapes of mid or lower back vertebral junctions and $28 \%$ presented partial or complete fusion of at least one of the spinal junctions. Similarly, Stubbs et al. (2006) found that out of 120 horses examined, 33\% presented abnormalities in the lumbar and sacral areas; thoroughbreds appeared more affected than Standardbreds (40\% versus 0\%). The authors suggest that variations at the lumbo-sacral junction (shape, attrition), an area of extreme mobility, may modify the horses' motion in this region and directly impact the pathogenesis of equine back pain.

\section{Working Conditions as a Source of Emotional Tensions}

An additional source of back pain is emotional tension: according to Ridgway and Harman (1999), pain and psychological stress may induce an extension of the spine ("hollowing the back") and an increased muscular tension at neck or back. Several authors also suggested that emotions are a possible source of back disorders (humans: Dionne et al., 2005; Houtman, Bongers, Smulders, \& Kompier, 1994; horses: Ridgway \& Harman, 1999). Riding per se may be both a source of emotion (Schmidt, Aurich, Möstl, Müller, \& Aurich, 2010) and of physical constraints, leading to a double potential effect on the emergence of back disorders (Hausberger et al., 2009, 2011). The type of training may also affect back tension through emotional impacts. Thus, in a training task where the horses had to learn to go backwards in response to a vocal order, the horses trained using a "classical" negative reinforcement (stopping of a mild agitation of a whip in front of the horse when the response is obtained, Skinner, 1938) went backwards with a high and hollow neck, which may induce an increase of vertebral constraints (see Waldern et al., 2009) whereas those trained using a positive reinforcement (food reward as soon as the horse gave the appropriate response, Skinner, 1938) were observed more with a round neck (Sankey et al., 2010). Steady head carriages and roundness (here related to the use of a positive reinforcement) reflect calmness and spine welfare (Egenwall et al., 2012; von Borstel et al., 2009; Waldern et al., 2009; Warren- 
Smith \& McGreevy, 2007). The observed prevalence of negative reinforcement and punishment in the current education of horses (Warren-Smith \& McGreevy, 2007) might lead to repeated undesired postures that might become chronic and hence a source of back disorders, even outside of work.

\section{Riding as a Source of Back Disorders: Anatomical Evidence}

Paleopathology is an important way of studying the evolution of horse husbandry. Archaeologists have shown that certain abnormalities of the caudal thoracic vertebrae in Iron Age horses could be related to riding (Levine, 1999; Levine, Bailey, Whitwell, \& Jeffcott, 2000). They seem to be characteristic of riding bareback or with a pad (Levine, 2005). The anatomical examination of Exmoor ponies living in semi-natural conditions and never ridden showed that they were exempt of these abnormalities whatever their age (Levine, 2005). Cook (2011) compared 66 mandibles of domestic horses and 12 of free ranging horses (feral and Przewalsky). It appeared that $88 \%$ of domestic horses' mandibles presented bone spur formation on the interdental space or erosion of dentine in the premolar, whereas feral and Przewalski horses were free of these lesions. The close relations between mouth and back disorders are further explained in the manuscript (see section "Behavioral Signs at Work Confirming the Negative Impact of Working Conditions" in this paper).

Another set of data emphasizes differences in the prevalence and type of vertebral disorders according to the discipline performed. Thus, while it is considered that western show horses suffer back pain as the musculoskeletal system is particularly challenged (Kobluk \& Gross, 1996). Fonseca et al. (2006) found differences in the type and location of the lesions according to the discipline in 24 western riding horses. Comparisons were made between three disciplines: cutting, where the horse and rider demonstrate their abilities to handle cattle, barrel where the horse and rider have to complete a cloverleaf pattern around preset barrels in the fastest time, and reining where the riders guide the horses through a precise pattern of circles, spins, and stops to test the responsiveness of the horse. There were more dorsal ligament strains in cutting horses, dorsal arthritis in barrel horses and muscular lesions in reining horses. The lesions were mostly found in the caudal part of the lumbar area in the cutting horses, whereas they were mostly located in the cranial lumbar area for the barrel horses. Dressage and show jumping horses were more at risk to develop back lesions in the caudal part of the spine than horses used in racing, eventing, and leisure (Dyson \& Murray, 2003). The type and location of vertebral injuries also differed: jumping horses were more likely to present crowding and overriding of the dorsal spinous processes in the caudal thoracic and cranial lumbar regions (Jeffcott, 1980), and the sacro-iliac junction was more affected in jumping and dressage than in eventing and leisure horses (Dyson \& Murray, 2003).

As the requirements differ according to the discipline performed (leading to various prevalences, locations, and types of back disorders in the horses), it seems essential to have a closer look on the riders' actions and their impact on the horses' back disorders.

\section{Focus on Riding Techniques}

\section{Rider's Pressure on the Horse's Back}

According to Haussler (1997), back disorders result from a probable addition of potential inappropriate conformation, poor saddle-fitting, and improper riding techniques. The mere fact of carrying a rider leads horses to have shorter stride lengths and a longer stride duration, as an attempt to compensate the rider's weight by increasing the contact with the ground (Morales et al., 1998). Being ridden by an experienced rider, with a good seat, may improve the horse's balance and stability (Greve \& Dyson, 2013; Peham, Licka, Schobesberger, \& Meschan, 2004). However, the forces acting on the horse's back may reach three times the rider's weight and may thus represent an enormous stress (Peham et al., 2010). The risk of injuries increases drastically when horses are confronted with unskilled riders who are unable to follow the movement of the back. The persistent crookedness of the rider can cause asymmetry resulting in secondary back pain (Greve \& Dyson, 2013; Peham et al., 2010). 
The impact of the rider's presence may be modulated by the equipment used. Levine et al. (2000) suggested that the stress applied on the horses' back during riding could have been moderated by changes of saddle design in the Medieval period. Since the last decades, authors investigate the impact of saddle fitting on horse's back motion and consequently on the appearance of back disorders (Latif et al., 2010). Traditionally, horses are ridden with wooden tree saddles that are supposed to spread the charges on the back, if well fitted (Greve \& Dyson, 2014). However, the rigid frame of such saddles has to perfectly fit the horse's back at rest, inducing otherwise undesired peaks of pressures, and it cannot fully adapt to the back changes that occur during the different phases of the same gait and between different gaits (Greve \& Dyson, 2013, 2014). When comparing the use of rigid tree saddles (RT) and free tree saddles (FT), most studies show that if better adapted to the horse's back shape changes, FT saddles are also more unstable and lead to higher pressures under the rider's seat (Greve \& Dyson, 2013). Fifty-one\% of the 506 sport horses (amongst which show horses) studied by Greve \& Dyson (2014) were ridden with unfitted or unbalanced saddles. Such maladaptation is associated with an emergence/aggravation of back pain, lameness and gait abnormalities reflected by an elevated neck and extended back (Greve \& Dyson, 2013, 2014). On the other hand, bareback riding induces more focal pressure concentrations that may increase the risk of pressure-induced injury to the horse's epaxial musculature than riding with a RT saddle and these peaks of pressure are localized in areas particularly sensitive to pressure injuries (Clayton, Belock, Lavagnino, \& Kaiser, 2013).

\section{Direct Impact of the Rider's Actions}

According to the bow and string theory (Denoix, 1999), every action at the level of the head and neck will have consequences on the back kinematics. Yet, when ridden, horses are often stuck into nonnatural postures, with consequences on the back kinematics (Gomez-Alvarez et al., 2006; Rhodin, Johnston, Holm, Wennerstrand, \& Dreverno, 2005). In a large scale study conducted on photographs of young, advertised and feral horses, McGreevy, Harman, McLean, and Hawson (2010) showed that the head-neck angle requested by riders is significantly smaller than when the horses move freely, whatever the gait and the horse's "experience" in riding. Gomez-Alvarez et al. (2006) study showed that amongst six different head and neck positions, the extremely high posture was likely to be the most uncomfortable, leading to a significant decrease in the intra-vertebral pattern symmetry, an increase of lateral bending of the spine, an increased extension of the cranial part of the thoracolumbar area and a flexion in the caudally located part, which could be a risk of injury (Rhodin et al., 2009). To a lesser extent, these studies raise the question of the impact of hyperflexion ("Rollkur": an extremely flexed posture of the neck in which the nose of the horse touches its chest, Figure 1), which is a source of debate as it does mechanically put pressure on the spine (e.g., von Borstel et al., 2009). The high level dressage horses tested in their study did not accept the degree of flexion described in Janssen et al. (2003) as "Rollkur" (Rhodin et al., 2009). These biomechanical studies highlight the strong impact of "stucking" horses' head and neck in unnatural positions on the back kinematics: being ridden with high neck and head (Goodwin, McGreevy, Warran, \& McLean, 2009) or extremely flexed neck is a problem, both leading probably to different types of lesions. 


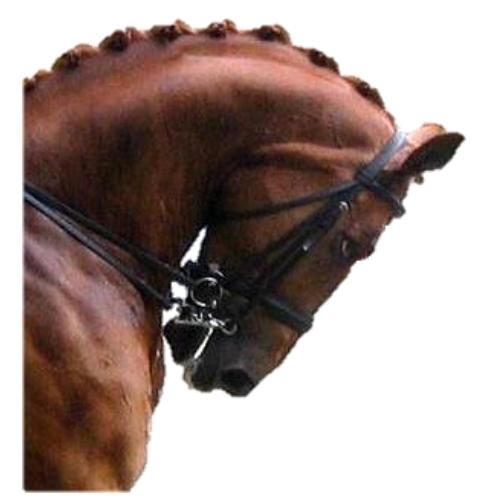

Figure 1. The "Rollkur" posture, also called "Hyperflexion." The horse's neck is extremely flexed, until the nose touches the chest.

Finally, evidence comes also from the differences in prevalence according to riding teaching. As mentioned earlier, anatomical data reveal differences between horses used in different disciplines (Fonseca et al., 2006; Kobluk \& Gross, 1996). This variability is also found in riding school horses: strong differences exist in the prevalence of back pain or vertebral disorders amongst schools, depending particularly on the trainer and training practices (Egenvall et al., 2009; Lesimple et al., 2010, 2013). More interestingly still, a recent study identified instruction horses as being at twice the risk to develop back pain evaluated through manual palpation relative to leisure or competition horses (Visser et al., 2014).

As mentioned by Hockenhull and Creighton (2012), rider based parameters would be best explored using observational studies. Therefore, Lesimple et al. (2010) performed a first study on 19 horse-rider pairs (11 geldings, eight mares; 7 - 22 years old; eight breeds) coming from two riding schools (respectively nine and ten horse-rider pairs, both teaching classical English riding) that offered the same management but differed in their teaching during beginners' riding lessons. In parallel, horses were submitted to an evaluation of the spine performed by an experienced ("blind") practitioner in their stall hence outside working time. Scan sampling during the lessons revealed that the time spent by horses in given postures at work (high/medium/low head position; hollow, horizontal/ round neck) was correlated with their spine's state as reported by the practitioner: horses that spent more time with high and/ or hollow neck at work presented more back disorders than horses spending more time with a low and/ or round neck. The question then arose of whether this had anything to do with the riders' positions. Riders' positions of hands (low/medium/high) and rein length were assessed using scan sampling as well. It appeared that riders' positions and horse's postures were strongly correlated: when the rider spent more time with high hands and short reins, horses spent more time with high and hollow neck, whereas low hands and long reins were associated with horses with low and round neck. At that stage though, it was impossible to know whether these correlations reflected the horse's expressions of potential pain leading to hollow neck and hence uncomfortable riding, or whether the riders' actions were responsible for the horse's inappropriate postures. Because the riders observed were beginners, they were under the strong influence of their teacher's recommendations. Therefore, the speech of the riding teachers was recorded during the lessons and then analyzed to extract these recommendations. Strong differences emerged between the teachers of the two riding schools: in the first school, the teacher was more interested in riders getting control over their horse, with terms like "shorten your reins", "keep distances", whereas in the second school more attention was given to the rider's position, with expressions such as "lower your hands" or "lengthen your reins" (Figure 2). Therefore, these findings suggest that it is indeed the riders' actions that are responsible for the horses' postures and with repetitions of lessons over time may have led to the chronic problems observed. 


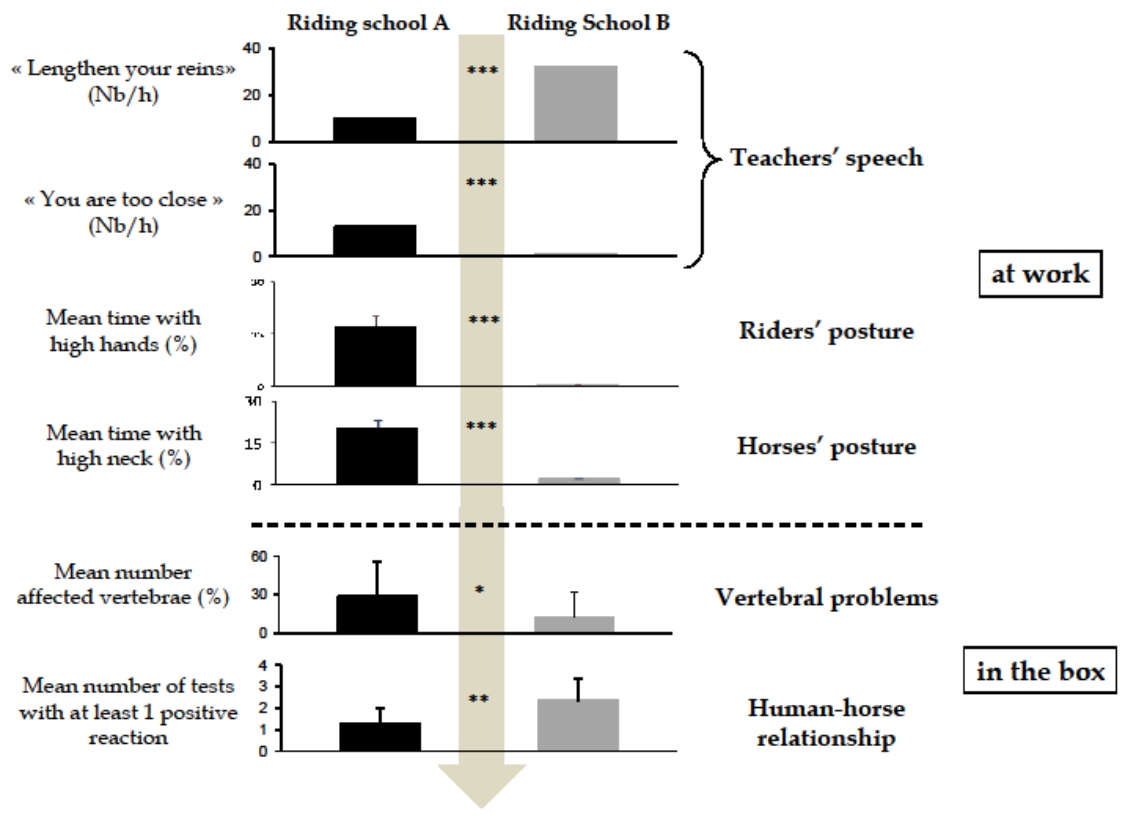

Figure 2. Impact of teaching practices on the riders' and horses' postures during lessons, and consequences on horses' back disorders and human-horse relationship. When the teacher was more attentive to the riders' positions, horses were less observed with high neck, had less back disorders and a better human-horse relationship. In the contrary, when the teacher paid more attention to the control of the horse, riders were more observed with high hands, horses with high neck and they presented more vertebral disorders and were more aggressive towards humans.

\section{Diving Deeper into Evidence}

In order to strengthen the results with a larger sample, we performed a further study on 108 horses (57 geldings, 51 mares, 3-30 years old, $\bar{\square}=14 \pm 0.5,13$ breeds, mostly unregistered horses) and their riders (beginners again) in 17 riding schools. The same exact scan sampling procedure was used as in Lesimple et al. (2010): the lessons were videotaped, and the riders' and horses' postures were recorded each time they crossed the field of the camera. As previously, the horses' neck evaluations involved:

1) height: horizontal $\left(0^{\circ}-45^{\circ} /\right.$ back line $)$, high $\left(>45^{\circ} /\right.$ back line $)$ and low $\left(<45^{\circ} /\right.$ back line $)$

2) shape: round (convex), flat (no curve) and hollow (concave).

Observations of riders' positions focused on:

1) hands' height: low (on the withers), high (more than $3 \mathrm{~cm}$ above the withers)

2) rein length: long ( $\geq 1$ neck length) and short ( $<1$ neck length)

3) rein tension: slacken (making a curve between the bit and the hand), taut (no curve).

Spearman correlation tests were used to assess the relationships between the riders' positions and horses' postures at work. The results confirmed that when riders hold their hands low (on the withers), horses were observed less with high and/ or hollow neck (Spearman correlation test, respectively $r_{s}=-0.23$ and $r_{s}=-0.30, p<0.01$ in both cases). On the contrary, hands above the withers (even slightly: $1 / 2$ fist $=3 \mathrm{~cm}$ high) were predictive of horses working less with low (respectively $r_{s}=-0.20, p<0.05$ ) and more with high and/or hollow neck (respectively $r_{s}=0.17$ and $r_{s}=0.21, p<0.05$ in all cases). Reins length and tension were also closely related to horses' postures. The more time the riders spent with long reins (more than a horse's neck), the more time horses spent with a low and round neck (respectively $r_{s}=$ 0.28 and $r_{s}=0.22, p<0.01$ in both cases) and the less with a high neck $\left(r_{s}=-0.37, p<0.001\right)$. On the contrary, short reins were associated with horses spending more time with high neck (Spearman 
correlation test, $r_{s}=0.31, p<0.001$ ) and less with low and round neck (respectively $r_{s}=-0.30, p<0.001$ and $\left.r_{s}=-0.20, p<0.05\right)$. Finally, the more time the riders were observed with slacken reins, the more time horses spent with a low neck $\left(r_{s}=0.64, p<0.001\right)$, whereas the more riders spent time with taut reins, the more time horses had high neck (respectively $r_{s}=0.32, p<0.001$ ) (Table 1 ). This extension of Lesimple et al.'s (2010) study clearly confirms and reinforces the earlier findings on the impact of riding techniques on the prevalence of horses' back disorders. We concentrated here on hands height and reins length, as it was found crucial in Lesimple et al. (2010). However, other components of the riders' position such as leg pressure and riders' seat might be of importance and should be addressed in further studies.

Table 1

Significant Correlations Between Horses' and Riders' Postures Observed at Work (Pace) During Beginner Lessons

\begin{tabular}{|c|c|c|c|c|c|c|c|}
\hline & & \multicolumn{2}{|c|}{ Hands' Height } & \multicolumn{2}{|c|}{ Reins' Length } & \multicolumn{2}{|c|}{ Reins' Tension } \\
\hline & & Low & High & Long & Short & Slacken & Taut \\
\hline \multirow{2}{*}{ Neck's height } & Low & & $-0.20 *$ & $0.28 * * *$ & $0.30 * * *$ & $0.64 * * *$ & $-0.35 * * *$ \\
\hline & High & $-0.23 * *$ & $0.17 *$ & $0.37 * * *$ & $0.31 * * *$ & $-0.37 * * *$ & $0.32 * * *$ \\
\hline \multirow{2}{*}{ Neck's shape } & Round & & & $0.22 * *$ & $-0.20 *$ & & \\
\hline & Concave & $-0.30 * * *$ & $0.21 *$ & & & & \\
\hline
\end{tabular}

Note. $N=142$ rider-horse pairs, 17 riding schools. The table indicates the Spearman's correlation tests' results (r values are indicated in the table).

$* p<0.05 . * * p<0.01 . * * * p<0.001$.

\section{Reliable Visible Indicators of Back Disorders}

\section{An Overlooked Problem}

Back disorders are very rarely identified by horses' professionals and owners (Cauvin, 1997; Haussler, 1997). In order to evaluate the degree of under-evaluation of back disorders, Lesimple et al. (2013) compared the evaluation of the prevalence of back disorders by the horses' caretaker with clinical examinations. Caretakers from 17 riding schools (one caretaker/school, 161 horses) were given a questionnaire about their horses' health status, including back disorders, while the horses' spines were evaluated using either manual palpation $(N=59)$ or sEMG $(N=102)$. It appeared that caretakers strongly under evaluated the prevalence of back disorders as they considered only 22 and four \% of the horses respectively as having back problems while 73 and $36 \%$ respectively were diagnosed as having back disorders (Figure 3). Visible reliable indicators of back disorders are thus clearly needed (Table 2). 
Table 2

Summary of the Physical, Postural and Behavioral Indicators Related to Back Pain

\begin{tabular}{|c|c|c|c|}
\hline & Validated indicators & To be validated & Related to back disorders \\
\hline \multirow[t]{4}{*}{ Physical } & $\begin{array}{l}\text { Asymetry of the pelvic bony } \\
\text { proeminences (Goff et al., 2008; } \\
\text { Haussler, 1996) }\end{array}$ & & $\begin{array}{l}\text { Orthopaedic disorders (Landman } \\
\text { et al., 2004; Mansmann et al 2010) }\end{array}$ \\
\hline & $\begin{array}{l}\text { Changes in gait (Fonseca et al,. } \\
\text { 2006; Goff et al., 2008; Tucker et } \\
\text { al., 1998) }\end{array}$ & & \\
\hline & $\begin{array}{l}\text { Lameness (Fonseca et al., 2006; } \\
\text { Goff et al., 2008; Landman et al., } \\
\text { 2004; Tucker et al., 1998) }\end{array}$ & & \\
\hline & $\begin{array}{l}\text { Abnormal weight distribution } \\
\text { (Goff et al., 2008) }\end{array}$ & & \\
\hline Postural & $\begin{array}{l}\text { Flat/ Hollow neck (Lesimple et } \\
\text { al., 2012) }\end{array}$ & $\begin{array}{l}\text { Stiff and flat back (De Cartier } \\
\text { d'yves \& Ödberg, 2005; Fureix et } \\
\text { al., 2011) }\end{array}$ & \\
\hline \multirow[t]{2}{*}{$\begin{array}{l}\text { Modification of } \\
\text { the repertoire }\end{array}$} & & $\begin{array}{l}\text { Teeth grinding, groaning } \\
\text { (Driessen \& Zaruco, 2007; } \\
\text { McGreevy et al., 2010) }\end{array}$ & $\begin{array}{l}\text { Head tossing/nodding (Aleman et } \\
\text { al., 2013, 2014; Cook, 1999, 2003; } \\
\text { Pickles et al., 2014; Veres-Nyéki } \\
\text { et al., 2012;) }\end{array}$ \\
\hline & & $\begin{array}{l}\text { Stereotypic / Abnormal behaviors } \\
\text { (Hausberger et al., 2009; Leme et } \\
\text { al., 2014) }\end{array}$ & \\
\hline \multirow[t]{2}{*}{$\begin{array}{l}\text { Modification of } \\
\text { the time budget }\end{array}$} & & $\begin{array}{l}\text { Increased restlesness (DeHeus et } \\
\text { al., 2010; Driessen \& Zaruco, } \\
\text { 2007; Head, 2012) } \\
\text { Pawing (Driessen \& Zaruco, } \\
\text { 2007) }\end{array}$ & "pain face" (de Heus et al., 2010) \\
\hline & & $\begin{array}{l}\text { Changes in recumbency time } \\
\text { (Driessen \& Zaruco, 2007) }\end{array}$ & \\
\hline $\begin{array}{l}\text { Modification of } \\
\text { interactive } \\
\text { behaviors }\end{array}$ & $\begin{array}{l}\text { Increased aggressiveness (Fureix } \\
\text { et al., 2010; Landman et al., 2004) }\end{array}$ & & \\
\hline \multirow[t]{2}{*}{ At work } & $\begin{array}{l}\text { High / Hollow neck (Lesimple et } \\
\text { al., 2010) }\end{array}$ & $\begin{array}{l}\text { Tail swishing, backing up, } \\
\text { attempt to buck, crabbing, } \\
\text { snorting, groaning (Driessen \& } \\
\text { Zarucco, 2007; Hall et al., 2013; } \\
\text { Head et al., 2012; von Borstel et } \\
\text { al., 2009; Wennerstrand et al., } \\
\text { 2004) }\end{array}$ & \\
\hline & & Headshaking (Cook 1999, 2003) & $\begin{array}{l}\text { Conflict behaviors (Hockenhull } \\
\text { \& Creighton, 2012; McGreevy \& } \\
\text { McLean, 2005) }\end{array}$ \\
\hline
\end{tabular}




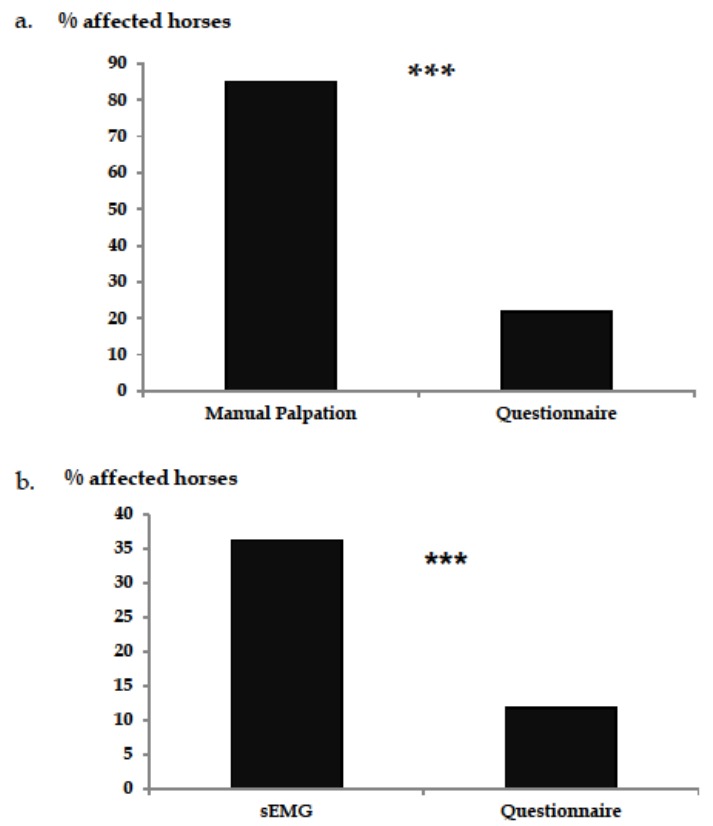

Figure 3. Evaluation of back problems through clinical evaluations and questionnaires. Note the similar discrepancies with questionnaires in both types of clinical evaluation. Chi square test, $* * * p<0.001$. a. Percentage of horses considered as affected via manual palpation on the left and questionnaire evaluation on the right. b. Percentage of horses considered as affected via sEMG on the left and questionnaire evaluations on the right. From Lesimple et al. (2013), BMV Veterinary Research.

\section{Behavioral Signs at Work Confirming the Negative Impact of Working Conditions}

Riding may thus exert constraints on the horses' spine, through bit actions in the mouth (Cook, 1999), neck positioning due to rein tension or side reins (Lesimple et al., 2010; von Borstel et al., 2009) and sitting due to riders' seat balance and/or saddle characteristics (e.g., Greve \& Dyson, 2013). Horses are then likely to experience discomfort or even pain and regular expressions of conflict behaviors at work are reported (McGreevy \& McLean, 2005). In an owner survey performed on 791 horses, it appeared that $84 \%$ of the horses showed resistance (e.g., not slowing), $61 \%$ expressed discomfort, $31 \%$ had jumping problems (e.g., refusals) and $22 \%$ had extreme conflicts with their rider (Hockenhull \& Creighton, 2012). A multivariate regression ranked the impact of the saddle type and the use of artificial riding aids (whip, spurs, martingale, running/draw reins, drop/flash nosebands) amongst the most important factors of expressed discomfort for the horses.

The negative effect of bit actions and rein tension are rather obvious when horses open the mouth, perform head shaking or tossing during riding (e.g., McGreevy \& McLean, 2005). Conditioning experiments showed that both naïve (2-year-old horses, never ridden, Christensen, Zharkikh, Antoine, \& Malmkvist, 2011) and experienced (6 to 23-year old horses used for teaching or competition, von Borstel et al., 2009) horses try to escape the pressure of the bit in their mouth. In both studies, horses expressed more defense behaviors such as opening the mouth and shaking the head when the pressure exerted in the mouth increased.

Bit pressure can lead to pain through the mandibular branch of the trigeminal nerve, which could explain the head tossing and shaking (Aleman et al., 2013, 2014), whereas pain, itching, or tingling sensations transmitted by the maxillary nerve to the region of the muzzle would some of explain the muzzle rubbing, sneezing, and snorting observed at work (Cook 1999, 2003; Pickles et al., 2014; VeresNyéki et al., 2012). In all of these cases, avoidance of the bit led to neck elevation, which is recognized as both a source and potential indicator of back disorders (see sections above, "Back Disorders: Prevalence 
and Diagnosis Tools" and "Sources of Back Disorders: Anatomy, Emotions and Work" in this paper; Quick \& Warren-Smith, 2009).

Several other behavioral patterns are commonly recognized as "conflict behaviors" (reflecting at least discomfort) in the equine world: tail-swishing, backing up, change in pace, attempt to buck, crabbing, abnormal oral behavior, ears pinned backwards, head-tossing, nose tilting, visible eye-white, stumbling, snorting and groaning are the most frequently reported (Driessen \& Zarucco, 2007; Hall et al., 2013; Head et al., 2012; McGreevy et al., 2010; von Borstel et al., 2009; Wennerstrand et al., 2004). However, there is a lack of clear and objective definitions.

\section{Chronic Behavioral and Physical Indicators of Back Pain}

Physical indices. Back disorders may also be visible through subtle changes in gaits, lameness or abnormal weight distribution (Ashley, Waterman-Pearson, \& Whay, 2005; Fonseca et al., 2006; Goff et al., 2008; Landman et al., 2004; Tucker et al., 1998). A study recently conducted on 3000 leisure and low level competition horses revealed that $19.3 \%$ of horses had gait abnormalities ranging from minor problems to overt lameness (Visser et al., 2014). In a study conducted on 1,204 horses, Landmann et al. (2004) suggested that horses with orthopedic disorders were much more likely to suffer back pain than control horses (34.8\% against $11.8 \%$ of the control population). Apart from declared lameness, feet anatomy may indicate or be a source of back disorders: long toes in the hind feet were related to pain reaction to gluteal palpation and when the feet anatomy was corrected with adapted shoes, these painful reactions to palpation disappeared (Mansmann et al., 2010). Inappropriate shoeing may induce back disorders (Ridgway \& Harmann, 1999). However, lameness is neither always detected nor present despite serious back disorders (Landman et al., 2004), therefore, more clearly visible indicators are needed.

Postural changes. When trying to test the impact of the "Rollkur" posture on the behavior of horses, De Cartier d'Yves \& Ödberg (2005) discovered that they could not obtain this position with riding school horses whose necks were too stiff and flat for that. We wondered whether these stiffness and flatness could be characteristic of back disorders. We developed a novel approach of assessment of the whole body posture that could be, contrarily to most kinematics studies, used in the field situation and on a large sample of horses: geometric morphometry (Fureix et al., 2011). In this study, domestic leisure horses living in semi natural conditions and riding school horses living in individual stalls with restricted diet were equipped with eight landmarks placed on the horses' right side in a sagittal plane, in relation to skeletal or muscular cues (enabling consistent reproduction of positioning) along the spine (Figure 4). Comparing the postures of these horses when walking led in hand, it appeared that they differed strikingly: while the leisure population was characterized by roundness in the neck and hindquarters, the riding school horses (issued from three riding schools) shared the same flat neck and body posture, confirming the observation of De Cartier et al. (2005) (Figure 5). Further investigation revealed that these leisure horses were exempt or only slightly affected by back disorders while $73 \%$ of the riding population was severely affected (Fureix et al., 2010, Lesimple et al., 2012). Stiffness and flatness of the back might be good indicators of back pain, but may be overlooked in riding schools where all horses are ridden the same way ("shared riding techniques"). 
Lesimple et al. 170

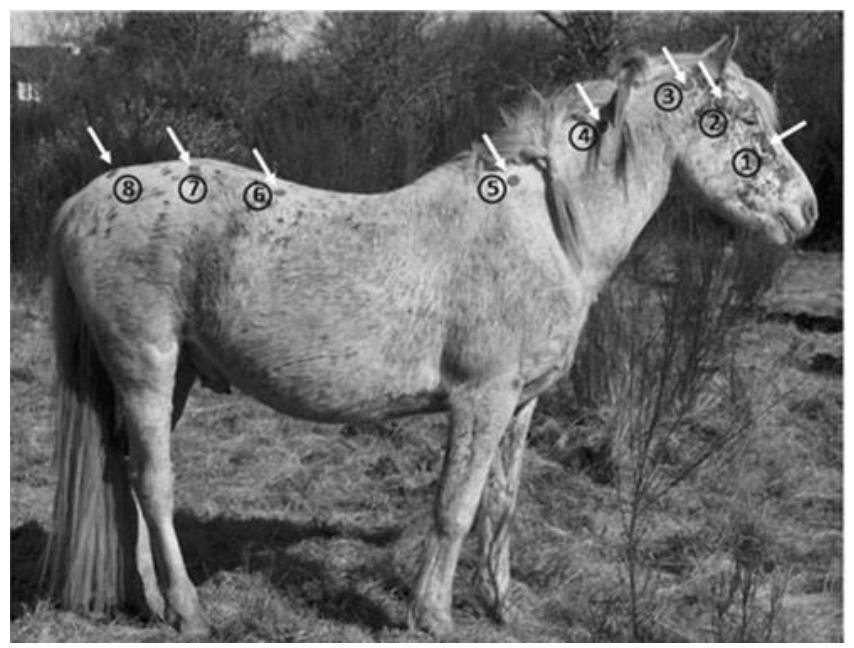

Figure 4. The eight landmarks positions. Landmarks were stuck onto the horse's right side and placed in relation to skeletal or muscular cues on: the nasal bone under the eye, $2 \mathrm{~cm}$ in front of the zygomatic process (landmark 1); the temporo-maxillary joint (2); the atlas (3); the trapezium cervical ligament (4); the cervico-thoracic (5); the thoracolumbar (6); and the lumbo-sacral (7) junctions and the first coccygeal vertebra; (8). From Fureix et al. (2011), Naturwissenschaften.

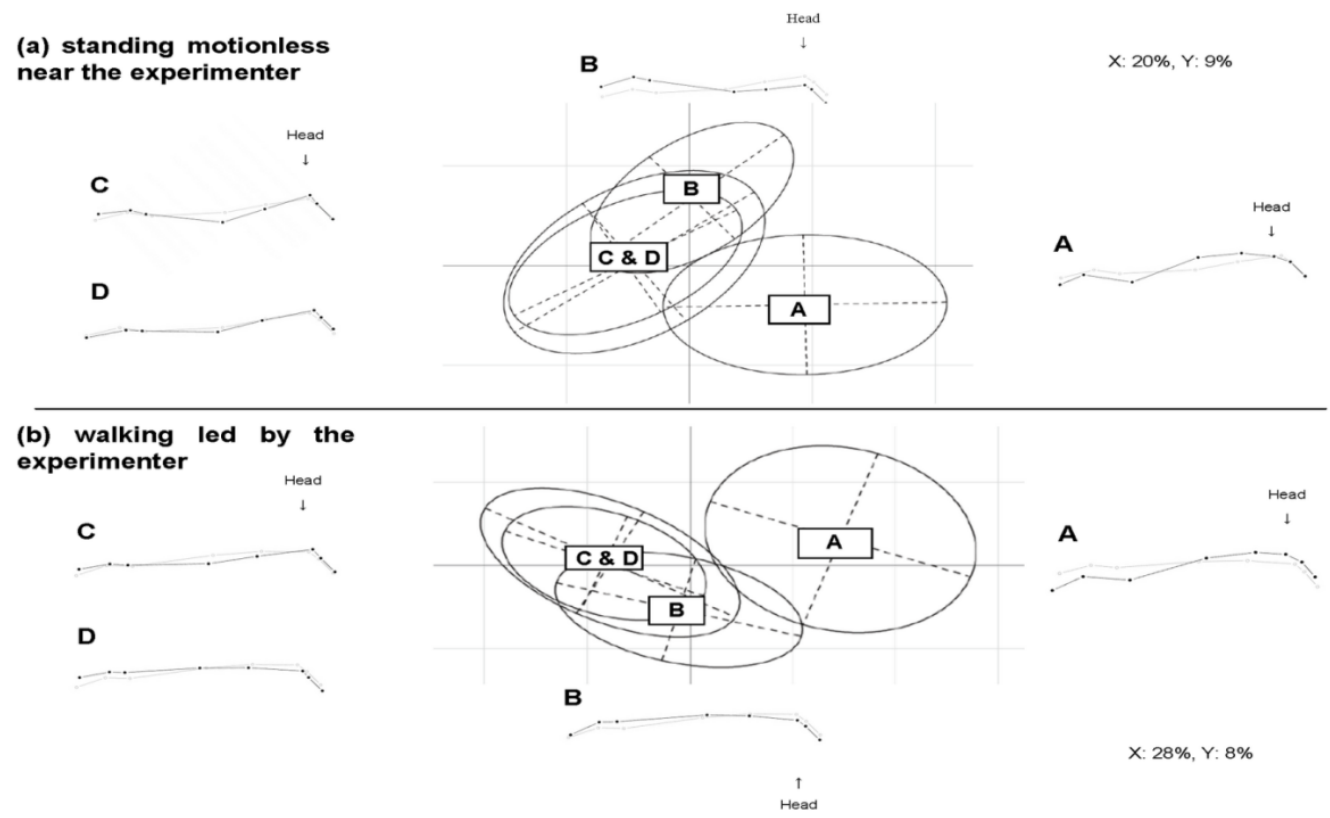

Figure 5. Postures in relation to behaviors at the group level. Lower case letters (a) and (b) refer to the parts of the figure and capital letters A, B, C, D to the riding schools. Principal component analysis (thin-plate spline (TPS) relative warp analysis, axes 2 and 3) based on TPS shape parameters and corresponding postures (black lines) as depicted by deformation grids. Barycentres of the observed postures (letters) and distribution values (showing the range of variation between observed postures for the behavior, represented on the graph by a circle around letters) are represented for a leisure horse, B, C and D horses from riding school B, riding school $\mathrm{C}$ and riding school D. Mean postures (representation extracted from TPS deformation grids) are represented for each population of horses (from A to D) while (a) standing motionless near the experimenter and (b) walking led by the experimenter. Axis 1 (not shown) explained respectively 50.80\% of the postural variation when horses stood motionless and $49.70 \%$ when horses walked (variation occurred in neck height). For both behaviors considered, the inter-group postural variation occurred mainly in horses' neck height and back roundness: leisure horses (A) had higher necks and back roundness than horses from riding schools (B, C and D). Distribution along axis 3 revealed that horses' postures also differed among riding schools: horses from riding school B had on average more straight and flat posture than those from riding schools $\mathrm{C}$ and $\mathrm{D}$. 
The highest postural difference observed was in the neck roundness, which is in accordance with the bow and string theory (Denoix, 1999). Therefore, we performed a further study that concentrated on the reliability of neck shape outside work as a potential visible indicator of back disorders (Lesimple et al., 2012). Again leisure horses living in semi natural conditions and riding school horses were submitted to a clinical evaluation of back disorders via sEMG measurement, while the neck shape was measured based on photographs using angles. The above mentioned procedure was used for the sEMG evaluation. In parallel, the same horses were equipped with 5 landmarks placed on their side on the head and neck, in relation to skeletal cues, and photographed when standing and walking while being held with a loose rope by an experimenter. The photographs were made on a regular ground, in a quiet environment, and horses were free to hold their head and neck as they wanted. Based on these photographs, different angles were measured, from the withers to the zygomatic apophysis, using usual trigonometrical rules in order to quantitatively evaluate neck height and roundness (Figure 6). The results showed that muscular activity at the different cervical locations were predictive of that obtained at different points along the spine, confirming that the cervical area reflects the overall spine state. A hollow neck was associated with a higher prevalence of back disorders all along the spine (Table 3). Significant differences were observed between the two populations: the leisure horses presented less vertebral disorders and a rounder neck both when standing and walking than the riding school horses. Overall, neck shape outside work appears therefore as a very promising indicator of back disorders. The difference between populations may reflect the differences in the way of life (less restrictions and hence better welfare in the leisure horses) but also, and probably mainly, the differences in the riding techniques used as the leisure horses were ridden with low hands and slacken reins contrarily to the studied riding school horses (see sections "Diving Deeper into Evidence", and "Direct Impact of the Rider's Actions" in this paper). 


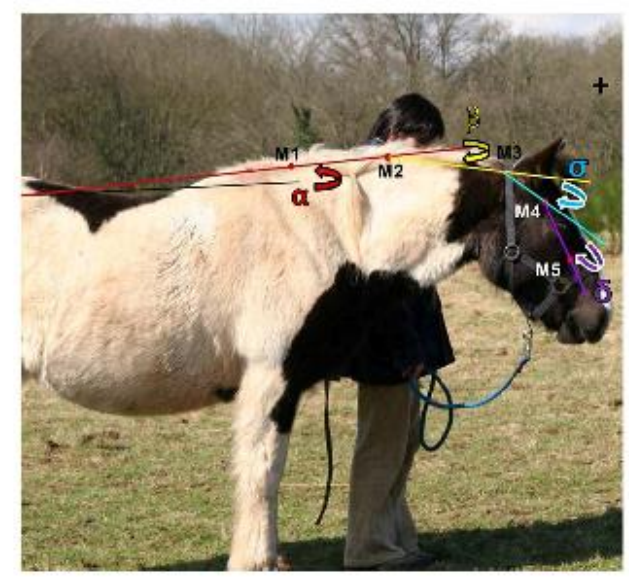

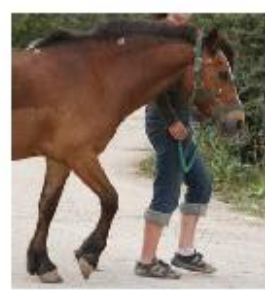

Angle $\beta<0$

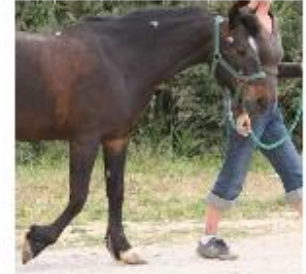

Angle $\beta=0$

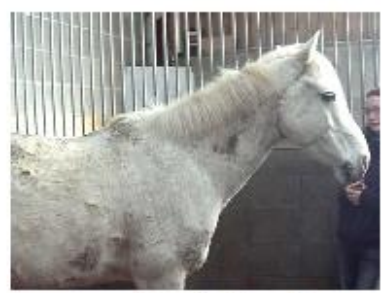

Angle $\beta>0$

Back problems

Figure 6. Representation of angles for neck posture measurement. $\alpha$ represents the neck's elevation, $\beta$ represents the neck's curve and $\sigma$ represent the M3-M5 angle (head-neck angle). On the left: round neck. In the middle: flat neck. On the right: hollow neck.

Table 3

Correlations between sEMG Measures Along the Spine) and the Horses' Neck Shape Angle

\begin{tabular}{ccccccc}
\hline & \multicolumn{6}{c}{ Muscular activity } \\
\cline { 2 - 6 } & $\mathrm{C} 3$ & $\mathrm{C} 5$ & $\mathrm{~T} 1$ & $\mathrm{~T} 3$ & $\mathrm{~L} 5$ & $\mathrm{~S} 1$ \\
\hline $\begin{array}{c}\text { a angle when } \\
\text { standing }\end{array}$ & $0.53 * *$ & $0.57 * *$ & $0.57 * *$ & $0.75 * * *$ & $0.79 * * *$ & $0.54 * *$
\end{tabular}

Note. The bigger the $\beta$ angle, the higher the muscular activity: a hollow neck was associated with a higher prevalence of back disorders all along the spine. From Lesimple et al. (2012). The table indicates the Spearman's correlation tests' results $(r$ values are indicated in the table).

$* p<0.05 . * * p<0.02 . * * * p<0.001$.

\section{Chronic Behavioral Changes}

Modification of the behavioral repertoire. Teeth grinding, groaning, and "abnormal exploratory behaviors" were reported in horses with back pain (Driessen \& Zaruco, 2007; McGreevy et al., 2010), however no details are available on the behavioral patterns included in the "abnormal exploration behaviors," preventing their identification by other observers. 
Hausberger et al. (2009) investigated the impact of the discipline on the expression of stereotypic behaviors. Their observation of horses of the same facility, differing only in the discipline performed, highlighted that the type and occurrences of stereotypic behaviors differed according to the discipline: voltige horses (that turn in circles around a lunging person, carrying some gymnasts) appeared to be the least prone to stereotypic behaviors and performed relatively "mild types" such as tongue play, whereas dressage/high-school horses presented the highest incidence and most disabling types of stereotypic behaviors (cribbing/ windsucking: The horse grasps a fixed object with its incisors, pulls back, and draws air into its esophagus while emitting a characteristic pharyngeal grunt; head shaking: The horse bobs repetitively its head up and down or tosses its head in recurrent and sudden bouts; Mills, 2005). Dressage and high school horses are both requested to refrain from expressing emotions and have strong physical constraints on their movements that lead to chronic excessive emotionality and favor back disorders: "suppressed emotions" are a known cause of back disorders in humans (Dionne et al., 2005) but also in horses (Ridgway \& Harman, 1999).

According to Ödberg (1978), the emergence of stereotypic behavior follows three steps: (1) trying to avoid a situation, (2) automatization of behavior in the situation, (3) emancipation: the behavior is performed independently of the situation. Some of the stereotypic behaviors observed, such as tongue play, may have developed this way, from trying to avoid pressure in the mouth to performing that behavior in their stalls, away from the original restraint. This possible lasting effect of strong bit actions has been suggested for head shaking (Cook 1999, 2003), as it might cause pain at the trigeminal nerve and may lead to an hypersensitivity of the horses in the mouth (Aleman et al., 2013, 2014). This sensitivity might be enhanced when horses have a hard permanent contact with their rider's hand and flexed cervical vertebrae as in many current dressage situations. Thus, the presence of headshaking might be the result of deleterious working conditions and postures associated with back disorders.

In a study conducted in equestrian centers in Brazil, Leme et al. (2014) found the highest prevalence of abnormal behaviors in rodeo $(95.5 \%)$ and horseback riding (74.6\%) horses compared to outdoor leisure riding, foals, reining or show jumping horses. In addition, rodeo horses that experienced the hardest management conditions (physically and psychologically) were also more prone to develop wounds and colic, compared to leisure, sport and horseback riding horses. Thus both physical and emotional stress can explain the high prevalence and types of stereotypies observed in these horses.

These results give a new view of the impact of work as a source of chronic (outside work) disorders: although non-specific, these abnormal / stereotypic behaviors performed in the stalls should question the possibility that they reflect back discomfort or pain.

Modification of the time budget. Modification of horses' time budget is mentioned more frequently but descriptions remain vague. Increased restlessness (DeHeus et al., 2010; Driessen \& Zaruco, 2007; Head, 2012), pawing, reduced locomotion and changes in recumbency time (Driessen \& Zaruco, 2007) are reported in cases of recognized back disorders. Concerning the changes in recumbency time, increased and decreased time spent recumbent are both considered as potential indicators of musculoskeletal disorders. However, no "baseline" is mentioned, making it impossible to objectively identify them by other observers. In a study conducted on six warmblood riding school mares, De Heus et al. (2010) also recorded the item "pain face" as defined by Fraser (1969), meaning "a fixed stare, the eyes tend to be puckered slightly, the ears are held back slightly, and the nostrils are dilated" during back pain evaluation via pressure algometer. Here again, the evaluation was based on the subjective perception of the experimenter, and no objective measure is available. Behavioral reactions are generally used as "complementary" information and based on subjective perceptions.

\section{Modification in Interactive Behaviors}

The existing evidence. Chronic back pain is identified as a source of irritability and bad temper in humans (Dionne et al., 2005) as well as in horses (Cauvin, 1997; Landman et al., 2004). Fureix et al. (2010) submitted 59 riding school horses to five behavioral tests in order to evaluate the human-horse 
relationship while their spine was examined independently at rest by an experienced practitioner. It appeared that more than $75 \%$ of the severely affected horses were aggressive towards the experimenter, while only $50 \%$ of the healthy ones were. Moreover, the percentage of affected vertebrae was negatively correlated with the number of positive reactions expressed by horses towards the experimenter during the behavioral tests: the less affected the horses were, the more they were positive towards the experimenter (Figure 7).

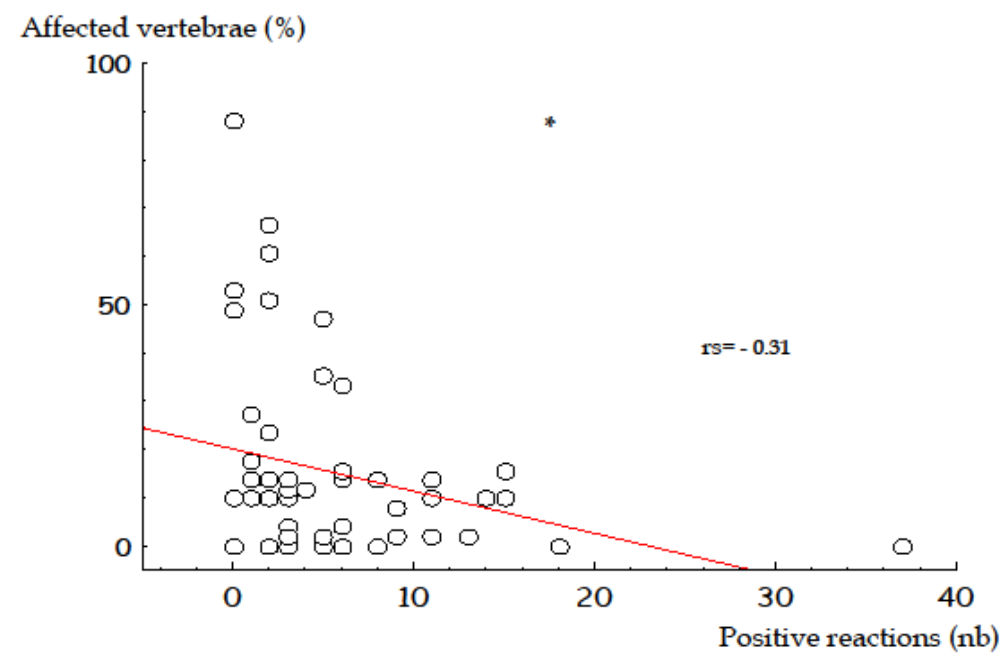

Figure 7. Correlation between the percentage of affected vertebrae and the number of positive reactions in behavioral tests. The more the vertebrae were affected, the less positive reactions the horses made. Spearman correlation test, $* p<0.05$. From Fureix et al. (2010), PloS ONE.

Confirming the link between aggressiveness and back disorders. A further study was conducted on 55 horses ( 29 geldings, 26 mares, aged $6-23$ years old, $\bar{\square}=13.8 \pm 0.6$, nine breeds, mostly French ponies and unregistered animals) coming from six riding schools across France using the same type of procedure. On the first hand, these horses were submitted to four human-horse relationship tests commonly used in the literature (Hausberger et al., 2008 for a review): the motionless person test (the experimenter stays motionless in the box), the approach contact test (the experimenter enters the box and tries to touch the horses' shoulder), the sudden approach test (the experimenter appears suddenly at the door of the box while the horse is feeding head down) and the halter fitting test (the experimenter enters the box and tries to fit the halter). In parallel, their spine was evaluated via sEMG (Lesimple et al., 2012). Strong correlations appeared between behavioral reactions towards the experimenter and muscular activity, in particular at the level of the caudal part of the neck and the cranial part of the thoracic area. Thus, aggressiveness was positively correlated to the muscular activity (reflecting back disorders, see Lesimple et al., 2012 and the section "Back Disorders: Prevalence and Diagnosis Tools" in this paper). The more horses had a high muscular activity at $\mathrm{C} 7$ and $\mathrm{T} 1$ level, the more they had aggressive reactions towards the experimenter (Spearman correlation tests, respectively $r_{s}=0.27$ and $r_{s}=0.31, p<0.05$ in both cases).

\section{Conclusion}

Although back disorders are one of the most common problems of the ridden horse, it remains one of the most undetected. Although signs of discomfort and conflict at work may be thought to be potential indicators of back disorders, they are generally not considered as a real problem that questions the rider's 
technique or equipment fitting and riders' actions or equipment are not supposed to lead to such major chronic problems. Even when the horse gets lame, it is rarely associated (in the owners' understanding) as a back pain problem. The studies described here are still too few but give real hope that back problems could be detected much earlier, and, still better, solved before they become chronic.

Postural elements are crucial both at rest and at work and it is important to remember the important role that the neck plays in the whole spine functioning of the horse (Denoix, 1999). Riding school teachers should be aware of the impact of their pupils' actions on the horses' spines, especially as back pain is associated with aggressiveness.

Further studies are clearly needed. Most of the horses' reactions are considered as "defensive" behaviors or postures are said "abnormal" or "changed" (DeHeus et al., 2010; Driessen \& Zaruco, 2007; Visser et al., 2014), but the variations are not quantified or described enough. Thus, if behaviors such as bucking, rearing, teeth grinding, tail-swishing, backing up, undesired changes in pace, attempt to buck, crabbing, nose tilting, eye-white visible, stumbling, groaning may be related in users' and professionals' minds as possible back disorders signals (Head, 2012), their description are scarce and there is no scientific evidence of their relationship with back disorders.

Overall, having a high and concave neck at (Gomez-Alvarez et al., 2006; Lesimple et al., 2010, Rhodin et al., 2005) and outside (Fureix et al 2011, Lesimple et al., 2012) work, gait asymmetry or lameness (Ashley et al., 2005; Fonseca et al., 2006; Greve \& Dyson, 2013; Peham et al., 2010) and shortened strides (Rhodin et al., 2009; Waldern et al., 2009; Weishaupt et al., 2006) appear as reliable, scientifically validated indicators of back disorders, as well as increased aggressiveness towards humans (Fureix et al., 2010; Hausberger et al., 2016) although this is less specific to back disorders.

It is also possible to detect the risk of developing back disorders at work: headshaking was related to mouth pain and raised neck (Cook 1999, 2003), which is known to increase the risks of back disorders (Denoix, 1999; Lesimple et al., 2010). Being restrained in an unnatural posture during working time is also pointed out both as a potential source of emotional and behavioral disturbance (Hausberger et al., 2009, 2011; von Borstel et al., 2009) and back disorders (Kobluk \& Gross, 1996; Rhodin et al., 2005). Thus, both headshaking and unnatural postures at work might be considered as a warning of potential back disorders' presence or at least as risk factors of their development.

Finally, in order to prevent or decrease the prevalence of back disorder, a particular attention has to be devoted to the equipment (the saddle in particular) and the riding practices (discipline and techniques). Efforts also have to be done concerning the early detection of subtle signals (behavioral and postural) that might alert owners to potential back disorders.

\section{References}

Aleman, M., Williams, D. C., Brosnan, R. J., Pickles, K. J., Berger, J., LeCouteur, R. A.,...Madigan, J. E. (2013). Sensory nerve conduction and somatosensory evoked potentials of the trigeminal nerve in horses with idiopathic headshaking. Journal of Veterinary Internal Medicine, 27, 1571-1580.

Aleman, M., Rhodes, D., Williams, D. C., Guedes, A., \& Madigan, J. E. (2014). Sensory evoked potentials of the trigeminal nerve for the diagnosis of idiopathic headshaking in a horse. Journal of Veterinary Internal Medicine, 28, 250-253.

Weiner, E., Hawkins, J., \& Burchfield, R. (1984). The Oxford Guide to the English Language (Oxford Reference). E. Weiner, J. Hawkins, R. Burchfield (Eds), United Kingdom: Oxford University Press.

Arena, J. G., Sherman, R. A., Bruno, G. M., \& Young, T. R. (1989). Electromyographic recordings of 5 types of low back pain subjects and non-pain controls in different positions. Pain, 37, 57-65. doi: 10.1016/03043959(89)90153-X

Arena, J. G., Sherman, R. A., Bruno, G. M., \& Young, T. R. (1991). Electromyographic recordings of low back pain subjects and non-pain controls in six different positions: Effect of pain levels. Pain, 45, 23-28.

Ashley, F. H., Waterman-Pearson, A. E., \& Whay, H. R. (2005). Behavioural assessment of pain in horses and donkeys: Application to clinical practice and future studies. Equine Veterinary Journal, 37, 565-575. doi: $10.2746 / 042516405775314826$ 
Banibrata, D. (2014). Prevalence of work-related musculoskeletal disorders among the brick field workers of West Bengal, India. Archives of Environemental Health, 69, 231-240.

Bateson, P. (1991). Assessment of pain in animals. Animal Behaviour, 42, 827-839. doi: 10.1016/S00033472(05)80127-7

Berkowitz, L. (1993). Pain and aggression: Some findings and implications. Motivation and Emotion, 17, $277-293$.

Christensen, J. W., Zharkikh, T. L., Antoine, A., \& Malmkvist, J. (2011). Rein tension acceptance in young horses in a voluntary test situation. Equine Veterinary Journal, 43, 223-228. doi: 10.1111/j.20423306.2010.00151.x

Clayton, H. M., Belock, B., Lavagnino, M., \& Kaiser, L. J. (2013). Forces and pressures on the horse's back during bareback riding. The Veterinary Journal, 195, 48-52.

Cook, W. R. (1999). Pathophysiology of bit control in the horse. Journal of Equine Veterinary Science, 19, 196204. doi: 10.1016/S0737-0806(99)80067-7

Cook, W. R. (2002). Bit-induced asphyxia in the horse: Elevation and dorsal displacement of the soft palate at exercise. Journal of Equine Veterinary Science, 22, 7-14.

Cook, W. R. (2003). Bit induced pain: A cause a fear, flight and facial neuralgia in the horse. Pferdheilkunde, 19, 75-82.

Cook, W. R. (2011). Damage by the bit to the equine interdental space and second lower premolar. Equine Veterinary Education, 23, 355-360. doi: 10.1111/j.2042-3292.2010.00167.x

Curie, S. R., \& Wang, J. L. (2004). Chronic back pain and major depression in the general Canadian population. Pain, 107, 54-60.

De Cartier d'Yves, A., \& Ödberg, F. (2005, August, $\left.26^{\text {th }}-27^{\text {th }}\right)$. A preliminary study on the relation between subjectively assessing dressage performance and objective welfare parameters. In P. McGreevy, A. McLean, A. Warren-Smith, D. Goodwin, N.Waran (eds) Conference proceedings of the first international equitation science symposium. Paper presented at the International Society for Equitation Science, Melbourne (pp. 89-110). Australia: Postgraduate Foundation in Veterinary Science.

DeHeus, P., van Oossanen, G., van Dierendonck, M., \& Back, W. (2010). A pressure algometer is a useful tool to objectively monitor the effect of diagnostic palpation by a physiotherapist in warmblood horses. Journal of Equine Veterinary Science, 30, 310-321. doi: 10.1016/j.jevs.2010.04.010

Denoix, J. M. (1999). Ultrasonographic evaluation of back lesions. Veterinary Clinics of North America: Equine Practices, 15,131-159.

Dionne, C. E., Bourbonnais, R., Fremont, P., Rossignol, M., Stock, S. R., \& Larocque, I. (2005). A clinical returnto-work rule for patients with back pain. Canadian Medical Association Journal, 172, 1559-1567. doi: 10.1503/cmaj.1041159

Driessen, B., \& Zarucco, L. (2007). Pain: From diagnosis to effective treatment. Clinical Technique in Equine Practices, 6, 126-134. doi: 10.1053/j.ctep.2007.05.005

Dyson, S. J., \& Murray, R. (2003). Pain associated with the sacroiliac joint region: A clinical study of 74 horses. The Equine Veterinary Journal, 35, 240-245. doi: 10.2746/042516403776148255

Egenvall, A. Eiseriö, M, \& Roepstorff, L. (2012). Pilot study of behavior responses in young riding horses using 2 methods of making transitions from trot to walk. Journal of Veterinary Behavior, 7, 157-168.

Egenvall, A., Lönnell, C., \& Roepstorff, L. (2009). Analysis of morbidity and mortality data in riding school horses, with special regard to locomotor problems. Preventive Veterinary Medicine, 88, 193-204. doi: 10.1016/j.prevetmed.2008.10.004

Egenvall, A., Penell, J. C., Bonnett, B. N., Olson, P., \& Pringle, J. (2006). Mortality of Swedish horses with complete life insurance between 1997 and 2000: Variations with age, sex, breed and diagnosis. Veterinary Records, 158, 397-406.

Faber, M. J, Schamhard, H., van Weeren, R., Johnston, C., Roepstorff, L., \& Barneveld, A. (2000). Basic threedimensional kinematics of the vertebral column of horses walking on a treadmill. American Journal of Veterinary Research, 61, 399-406. doi: 10.2460/ajvr.2000.61.399

Fonseca, B. P. A., Alves, A. L. G., Nicoletti, J. L. M., Thornassian, A., Hussni, C. A., \& Mikail, S. (2006). Thermography and ultrasonography in back pain diagnosis of equine athletes. Journal of Equine Veterinary Science, 26, 507-516. doi: 10.1016/j.jevs.2006.09.007

Fraser, J. A. (1969). Some observations on the behaviour of the horse in pain. The British Veterinary Journal, 125, $150-151$.

Fureix, C., Hausberger, M., Seneque, E., Morisset, S., Baylac, M., Cornette, R., ...Deleporte, P. (2011). Geometric morphometrics for ethologists: Improving the comparative study of behavioural postures. Naturwissenschaften, 98, 583-592. doi: 10.1007/s00114-011-0803-2 
Fureix, C., Menguy, H., \& Hausberger, M. (2010). Partners with bad temper: Reject or cure? A study of chronic pain and aggression in horses. PloS ONE, 5, e12434. doi: 10.1371/journal.pone.0012434

Garon, D. C., \& Leavitt, F. (1983). Chronic low back pain and depression. Journal of Clinical Psychology, 39, 486493.

Gillis, C. (1999). Spinal ligament pathology. Veterinary Clinics of North America: Equine Practices, 15, 97-101.

Goff, L. M., Jeffcott, L. B., Jasiewicz, J., \& McGowan, C. M. (2008). Structural and biomechanical aspects of equine sacroiliac joint function and their relationship to clinical disease. The Veterinary Journal, 176, 281293. doi: 10.1016/j.tvj1.2007.03.005

Gomez-Alvarez, C. B., Rhodin, M., Bobbert, M. F., Meyer, H., Weishaupt, M. A., Johnston, C., \& van Weerne, P. R. (2006). The effect of head and neck position on the thoracolumbar kinematics in the unridden horse. The Equine Veterinary Journal Supplement, 36, 445-451.

Goodwin, D., McGreevy, P., Warran, N., \& McLean, A. (2009). How equitation science can elucidate and refine horsemanship techniques. The Veterinary Journal, 181, 5-11. doi: 10.1016/j.tvj1.2009.03.023

Greve, L., \& Dyson, S. (2013). The horse-saddle-rider interaction. The Veterinary Journal, 195, 275-281. doi: 10.1016/j.tvj1.2012.10.020

Greve, L., \& Dyson, S. (2014). The interrelationship of lameness, saddle slip and back shape in the general sports horse population. The Equine Veterinary Journal, 46, 687-694. doi: 10.1111/evj.12222

Hall, C., Huws, N., White, C., Taylor, E., Owen, H., \& McGreevy, P. (2013). Assessment of ridden horse behavior. Journal of Veterinary Behaviour, 8, 62-73. doi: 10.1016/j.jveb.2012.05.005

Hausberger, M., Gautier, E., Biquand, V., Lunel, C., \& Jego, P. (2009). Could work be a source of behavioural disorders? A study in horses. PLoS ONE, 4,e7625. doi: 10.1371/journal.pone.0007625

Hausberger, M., Muller, C., \& Lunel, C. (2011). Does work affect personality? A study in horses. Plos One, 6, e14659. doi: 10.1371/journal.pone.0014659

Haussler, K. K. (1996). The lower back and pelvis of performance horses receive a closer look. Journal of Equine Veterinary Science, 16, 279-281. doi: 10.1016/S0737-0806(96)80220-6

Haussler, K. K. (1997, December, 7 - 10). Application of chiropractic principles and techniques to equine practice. In Proceedings of Annual Convention of the AAEP, Paper presented at the American Association of Equine Practitionner Annual Convention, Phoenix: American Association of Equine practitioners.

Haussler, K. K, \& Erb, H. N. (2006). Pressure algometry for the detection of induced back pain in horses: A preliminary study. The Equine Veterinary Journal, 38, 76-81. doi: 10.2746/042516406775374225.

Head, M. (2012). Diagnosis of equine back pain. Veterinary Nursing Journal, 27, 288-292.

Hockenhull, J., \& Creighton, E. (2012). Equipment and training factors associated with ridden behavior problems in UK leisure horses. Applied Animal Behaviour Science, 137, 36-42. doi: 10.1016/j.applanim.2012.01.007

Houtman, I., Bongers, P. M., Smulders, P., \& Kompier, M. (1994). Psychosocial stressors at work and musculoskeletal problems. Scandinavian Journal of Work Environment and Health, 20, 139-145.

Jeffcott, L. B. (1975). The diagnosis of diseases of the horse's back. Equine Veterinary Journal, 7, 9-19.

Jeffcott, L. B. (1979). Back problems in the horse - Look at past, present and future progress. Equine Veterinary Journal, 1, 129-136.

Jeffcott, L. B. (1980). Disorders of the thoracolumbar spine of the horse - A survey of 443 cases. Equine Veterinary Journal, 12, 197-210.

Johnson, B. J., Stover, S. M., Daft, B. M., Kinde, H., Read, D. H., Barr, B. C., \& Blanchard, P. (1994). Causes of death in racehorses over a 2 year period. Equine Veterinary Journal, 26, 327-330.

Jönsson, L., Roepstorff, L., Egenvall, A., Näsholm, A., Dalin, G., \& Philipsson, J. (2013). Prevalence of clinical findings at examinations of young Swedish warmblood riding horses. Acta Veterinaria Scandinavia, 55, 34-47. doi: 10.1186/1751-0147-55-34

Kirkaldy-Willis, W. H., \& Cassidy, J. D. (1985). Spinal manipulation in the treatment of low-back pain. Canadian Family Physician, 31, 535-540.

Kobluk, C. N., \& Gross G. M. (1996). Exercise intolerance and poor performance in western performance horses. Veterinary Clinics of North America: Equine Practes, 12, 581-606.

Landman, M. A. A., de Blaauw, J. A., van Weeren, P. R., \& Hofland, L. J. (2004). Field study of the prevalence of lameness in horses with back problems. Veterinary Records, 155, 165-168.

Latif, S. N., von Peinen, K., Wiestner, T., Bitschnau, C., Renk, B., \& Weishaupt, M. A. (2010). Saddle pressure patterns of three different training saddles (normal tree, flexible tree, treeless) in thoroughbred racehorse at trot and gallop. Equine Veterinary Journal, 42, 630-636. doi: 10.1111/j.2042-3306.2010.00237.x

Leme, D., Parsekian, A., Kanaan, V., \& Hötzel, M. (2014). Management, health and abnormal behaviors of horses: a survey in small equestrian centers in Brazil. Journal of Veterinary Behavior, 9, 114-118. 
Lesimple, C., Fureix, C., Biquand, V., \& Hausberger, M. (2013). Comparison of clinical evaluation of back disorders and human's evaluation of back pain in riding school horses. BMC Veterinary Research, 9, 209217. doi: 10.1186/1746-6148-9-209

Lesimple, C., Fureix, C., De Margerie, E., Sénèque, E., Menguy, H., \& Hausberger, M. (2012). Towards a postural indicator of back pain in horses (Equus caballus). PLoS ONE, 7, e44604. doi: 10.1371/journal.pone.0044604

Lesimple, C., Fureix, C., Menguy, H., \& Hausberger, M. (2010). Human direct actions may alter animal welfare: A study on horses (Equus caballus). PLoS ONE, 5, e10257. doi:10.1371/journal.pone.0010257

Levine, M. (1999). Botai and the origins of horse domestication. Journal of Anthropological Archaeology, 18, 2978. doi: 10.1006/jaar.1998.0332

Levine, M. A. (2005). Domestication and early history of the horse. In D. S. Mills \& S. M. McDonnell (Eds.), The domestic horse. The origins, development and management of its behaviour (pp. 5 - 22). Cambridge, UK: Cambridge University Press.

Levine, M., Bailey, G., Whitwell, K., \& Jeffcott, L. (2000). Paleopathology and horse domestication: The case of some iron age horses horn the Altai Mountains, Siberia. In G. Bailey, R. Charles, N. Winder (eds) Human ecodynamics. Symposia of the association for environmental archaeology (pp. 123-133). United Kingdom: Oxbow Books.

Licka, T., \& Peham, C. (1998). A method for evaluating the flexibility of the back of standing horses. Equine Veterinary Journal, 30, 412-415.

Malamed, R., Berger, J., Bain, M., Kass, P., \& Spier, S. (2010). Retrospective evaluation of crib-bitting and windsucking behaviours and owner-perceived behavioural traits as risk factors for colic in horses. Equine Veterinary Journal, 42, 686-692.

Mansmann, R. A., James, S., Blikslager, A. T., \& vom Orde, K. (2010). Long toes in the hind feet and pain in the gluteal region: An observational study of 77 horses. Journal of Equine Veterinary Science, 30, 720-726. doi: 10.1016/j.jevs.2010.11.007

McGreevy, P. D., \& McLean, A. (2005). Behavioural problems with the ridden horse. In D. S. Mills \& S. M. McDonnell (Eds.), The domestic horse. The origins, development and management of its behaviour (pp. 196 - 211). Cambridge, UK: Cambridge University Press.

McGreevy, P. D., Harman, A., McLean, A., \& Hawson, L. (2010). Over-flexing the horse's neck: A modern equestrian obsession? Journal of Equine Veterinary Behaviour, 5, 180-186. doi: 10.1016/j.jveb.2010.03.004

Mills, D. S. (2005). Repetitive movement problems in the horse. In D. S. Mills \& S. M. McDonnell (Eds.), The domestic horse. The origins, development and management of its behaviour (pp. 212-227). Cambridge, UK: Cambridge University Press.

Mohammed, H. O., Hill, T., \& Lowe, J. (1991). Risk factors associated with injuries in thoroughbred racehorses. Equine Veterinary Journal, 23, 445-448.

Morales, J. L., Mandchado, M., Vivo, J., Galisteo, A. M., Agüera, E., \& Miró, F. (1998). Angular kinematic patterns of limbs in elite and riding horses at trot. Equine Veterinary Journal, 30, 528-533. doi: 10.1111/j.20423306.1998.tb04529.x

Nagy, A., Dyson, S., \& Barr, A. (2010). Ultrasonographic findings in the lumbosacral joint of 43 horses with no clinical signs of back pain or hindlimb lameness. Veterinary Radiology and Ultrasound, 51, 533-539. doi: 10.1111/j.1740-8261.2010.01691.x

Nicol, C., Davidson, H., Harris, P., Waters, A., \& Wilson, A. (2002). Study of crib-biting and gastric inflammation and ulceration in young horses. Veterinary Records, 151, 658-662.

Ödberg, F. O. (1978). Abnormal behaviours: Atereotypies. Madrid: Proceedings of the 1st World Congress on Ethology as Applied to Zootechnies, 1, 475-480.

Peham, C., Kotschwar, B., Borkenhagen, B., Kuhnke, S., Molsner, J., \& Baltacis, A. (2010). A comparison of the forces acting on the horse's back and the stability of the rider's seat in different positions at the trot. The Veterinary Journal, 184, 56-59. doi: 10.1016/j.tvj1.2009.04.007

Peham, C., Licka, T., Schobesberger, H., \& Meschan, E. (2004). Influence of the rider on the variability of the equine gait. Human movement Science, 23, 663-671. doi: 10.1016/j.humov.2004.10.006

Pickles, K., Madigan, J., \& Aleman, M. (2014). Idiopathic headshaking: Is it still idiopathic? The Veterinary Journal, 201, 21-30.

Quick, J., \& Warren-Smith, A. (2009). Preliminary investigations of horses' (Equus caballus) responses to different bridles during foundation training. Journal of Veterinary Behaviour, 4, 169-176. 
Rhodin, M., Gomez-Alvarez, C. B., Bystrom, A., Johnston, C., van Weeren, P. R., Roepstorff, L., \& Weishaupt, M. A. (2009). The effect of different head and neck positions on the caudal back and hindlimb kinematics in the elite dressage horse at trot. Equine Veterinary Journal, 41, 274-279. doi: 10.2746/042516409X394436

Rhodin, M., Johnston, C., Holm, K. R., Wennerstrand, J., \& Dreverno, S. (2005). The influence of head and neck position on kinematics of the back in riding horses at the walk and trot. Equine Veterinary Journal, 37, 711. doi: 10.2746/0425164054406928

Ridgway, K., \& Harman, J. (1999). Equine back rehabilitation. Veterinary Clinics of North America: Equine Practices, 15, 263-280.

Sankey, C., Richard-Yris, M. A., Henry, S., Fureix, C., Nassur, F., \& Hausberger, M. (2010). Reinforcement as a mediator of the perception of humans by horses (Equus caballus). Animal Cognition, 13, 753-764.

Schmidt, A., Aurich, J. Möstl, E., Müller, J., \& Aurich, C. (2010). Changes in cortisol release and heart rate and heart rate variability during the initial training of 3-year-old sport horses. Hormones and Behavior, 58, 628-636.

Skinner, B. F. (1938). The behaviour of organisms. New York, NY: Appleton-Century-Crofts.

Stubbs, N. C., Hodges, P. W., Jeffcott, L. B., Cowin, G., Hodgson, D. R., \& McGowan, C. M. (2006). Functional anatomy of the caudal thoracolumbar and lumbosacral spine in the horse. Equine Veterinary Journal, 36, 393- 399.

Sullivan, K. A., Hill, A. E., \& Haussler, K. K. (2008). The effects of chiropractic, massage and phenylbutazone on spinal mechanical nociceptive thresholds in horses without clinical signs. Equine Veterinary Journal, 40, 14-20. doi: 10.2746/042516407X240456

Townsend, H. G. G. (1987). Pathogenesis of back pain in the horse. Equine Sports Medicine, 6, $29-32$.

Tucker, R. L., Schneider, R. K., Sondhof, A. H., Ragle, C. A., \& Tyler, J. W. (1998). Bone scintigraphy in the diagnosis of sacroiliac injury in twelve horses. Equine Veterinary Journal, 30, 390-395.

Varcoe-Cocks, K., Sagar, K. N., Jeffcott, L. B., \& McGowan, C. M. (2006). Pressure algometry to quantify muscle pain in racehorses with suspected sacroiliac dysfunction. Equine Veterinary Journal, 38, 558-562. doi: $10.2746 / 042516406 \times 154804$

Veres-Nyéki, K., Leandri, M., \& Spadavecchia, C. (2012). Nociceptive trigeminal reflexes in non-sedated horses. The Veterinary Journal, 191, 101-107.

Visser, K., Neijenhuis, F., de Graaf-Roelfsema, E., Wesselink, H. G. M., de Boer, J., van Wijhe-Kiezebrink, M. C., ...van Reenen, C. G. (2014). Risk factors associated with health disorders in sport and leisure horses in the Netherlands. Journal of Animal Science, 92, 844-855. doi: 10.2527/jas2013-6692

von Borstel, U., Heatly Duncan, I. J., Shoveller, A. K., Merkies, K., Keeling, L. J., \& Millman, S. T. (2009). Impact of riding in a coercively obtained rollkur posture on welfare and fear of performance horses. Applied Animal Behaviour Science, 116, 228-236. doi: 10.1016/j.applanim.2008.10.001

Waldern, N. M., Wiestner, T., von Peinen, K., Gomez-Alvarez, C. G., Roepstorff, L., Johnston, ...Weishaupt, M. A. (2009). Influence of different head-neck positions on vertical ground reaction forces, linear and time parameters in the unridden horse walking and trotting on a treadmill. Equine Veterinary Journal, 41, 268273. doi: 10.2746/042516409X397389

Wallin, L., Strandberg, E., Philipsson, J., \& Dalin, G. (2000). Estimates of longevity and causes of culling and death in Swedish warmblood and coldblood horses. Livestock Production Science, 63, 275-289. doi: 10.1016/S0301-6226(99)00126-8

Warren-Smith, A., \& McGreevy, P. (2007). The use of blended positive and negative reinforcement in shaping the halt response of horses (Equus caballus). Animal Welfare, 16, 481-488

Weishaupt, M. A., Wiestner, T., von Peinen, K., Waldern, N., Roepstorff, L., van Weeren, R., ...Johnston, C. (2006). Effect of head and neck position on vertical ground reaction forces and interlimb coordination in the dressage horse ridden at walk and trot on a treadmill. Equine Veterinary Journal supplement, 36, 387392.

Wennerstrand, J., Johnston, C., Roethlisberger-Holm, K., Erichsen, C., Eksell, P., \& Drevemo, S. (2004). Kinematic evaluation of the back in the sport horse with back pain. Equine Veterinary Journal, 36, 707-711. doi: $10.2746 / 0425164044848226$

Widanarko, B., Legg, S., Devereux, J., \& Stevenson, M. (2014). The combined effect of physical/organisational and/or environmental risk factors on the presence of work-related musculoskeletal symptoms and its consequences. Applied Ergonomy, 45, 1610-1625.

Zimmerman, M., Dyson, S., \& Murray, R. (2011). Comparison of radiographic and scintigraphic findings of the spinous processes in the equine thoracolumbar region. Veterinary Radiology and Ultrasound, 52, 661-671. doi: 10.1111/j.1740-8261.2011.01845.x 